\title{
ANALISA BOK (BIAYA OPERASI KENDARAAN) SHUTTLE SERVICE RUTE BANDUNG - JAKARTA SELATAN
}

\author{
Analysis Vehicles Operating Cost of Shuttle Service Route Bandung - Jakarta
}

\author{
Juang Akbardin', Andri Eka Putra² \\ ${ }^{1,2}$ Program Studi Teknik Sipil, FPTK, Universitas Pendidikan Indonesia \\ Jl. Setiabudi No. 229 Bandung \\ Email: akbardien@yahoo.co.id
}

\begin{abstract}
The opening of the toll road Cipularang provide opportunities for business people open a travel service (shuttle service) "point to point" are scattered in several points in Bandung. Another phenomenon occurs on the field gap between the performance of the travel srvices to the satisfaction of passengers. This, prompted the authors to conduct a study of the level of analytic of vehicle operating cost for services of travel. Due to limited funds, manpower, and time, the scope of this final study is limited to the South Jakarta - Bandung route. In this study using quantitative methods with descriptive analysis techniques. The data used were obtained from the results of a questionnaire survey / questionnaire and interview. The sampling technique is Probability Sampling is done using simple random sampling method with a sample of 390 respondents taken as users travel (shuttle service) Bandung-South Jakarta route. Data analysis using the method of Importance Performance Analysis. Based on the analysis, a gap in variable costs, travel time, and travel itineraries. Variable costs and passenger safety is still not good and a top priority for improvement.
\end{abstract}

Keywords: vehicle operating cost, performance, travel.

\begin{abstract}
Abstrak
Dibukanya jalan tol Cipularang memberi peluang bagi para pebisnis membuka layanan travel (shuttle service) "point to point" yang tersebar dibeberapa titik di Bandung. Fenomena lain di lapangan terjadi kesenjangan/gap antara kinerja pelayanan travel (shuttle service)dengan kepuasan penumpang. Hal ini, mendorong penulis untuk melakukan penelitian terhadap tingkat kepuasan penumpang atas layanan jasa travel. Karena keterbatasan dana, tenaga, dan waktu, maka lingkup studi Tugas Akhir ini dibatasi pada rute Bandung-Jakarta Selatan. Pada penelitian ini menggunakan metode kuantitatif dengan teknik analisis deskriptif. Data yang digunakan diperoleh dari hasil survei kuesioner/angket dan wawancara. Teknik sampling yang dilakukan adalah Probability Sampling menggunakan metode Simple Random sampling dengan jumlah sampel yang diambil sebanyak 390 responden pengguna jasa travel (shuttle service)rute Bandung-Jakarta Selatan. Analisis data penelitian menggunakan metode Importance Performance Analysis. Berdasarkan hasil analisis, terjadi kesenjangan pada variabel biaya, waktu tempuh, dan jadwal perjalanan. Variabel biaya dan keselamatan penumpang masih kurang baik dan menjadi prioritas utama untuk ditingkatkan.
\end{abstract}

Kata kunci : BOK, kinerja, travel.

\section{PENDAHULUAN}

Hadirnya angkutan travel (shuttle service) memberikan alternatif pilihan bagi penumpang sesuai dengan tujuan perjalanan. Fenomena lain di lapangan terjadi kesenjangan/gap antara kinerja pelayanan travel (shuttle service) dengan kepuasan penumpang.

Hal ini, mendorong penulis untuk melakukan penelitian terhadap Biaya Operasi Kendaraan travel (shuttle service) yang melayani rute Bandung-Jakarta Selatan yang ada di Kota Bandung.

Tujuan yang hendak dicapai dari penelitian ini adalah Menghitung biaya operasional kendaraan perusahaan travel (shuttle service) rute Bandung-Jakarta Selatan dalam menentukan besarnya tarif travel (shuttle service) yang sesuai dengan kemampuan dan kemauan konsumen pengguna jasa angkutan travel (shuttle service) rute Bandung-Jakarta Selatan PP. 
Biaya Operasi Kendaraan di definisikan sebagai pengorbanan dalam bentuk barang atau jasa yang diperlukan untuk menghasilkan jasa angkutan (F.D Hobbs, 1995). Perhitungan analisis BOK menggunakan analisis teoritis, yang artinya perhitungan dilakukan berdasarkan rumus empiris yang umum digunakan dengan menggunakan data sekunder. Perhitungan ini berdasarkan pada aturan Dinas Perhubungan Darat.

\section{METODE PENELITIAN}

Untuk mempermudah dan memberikan arah pada penelitian, maka dilakukan langkah-langkah penelitian sebagai berikut.

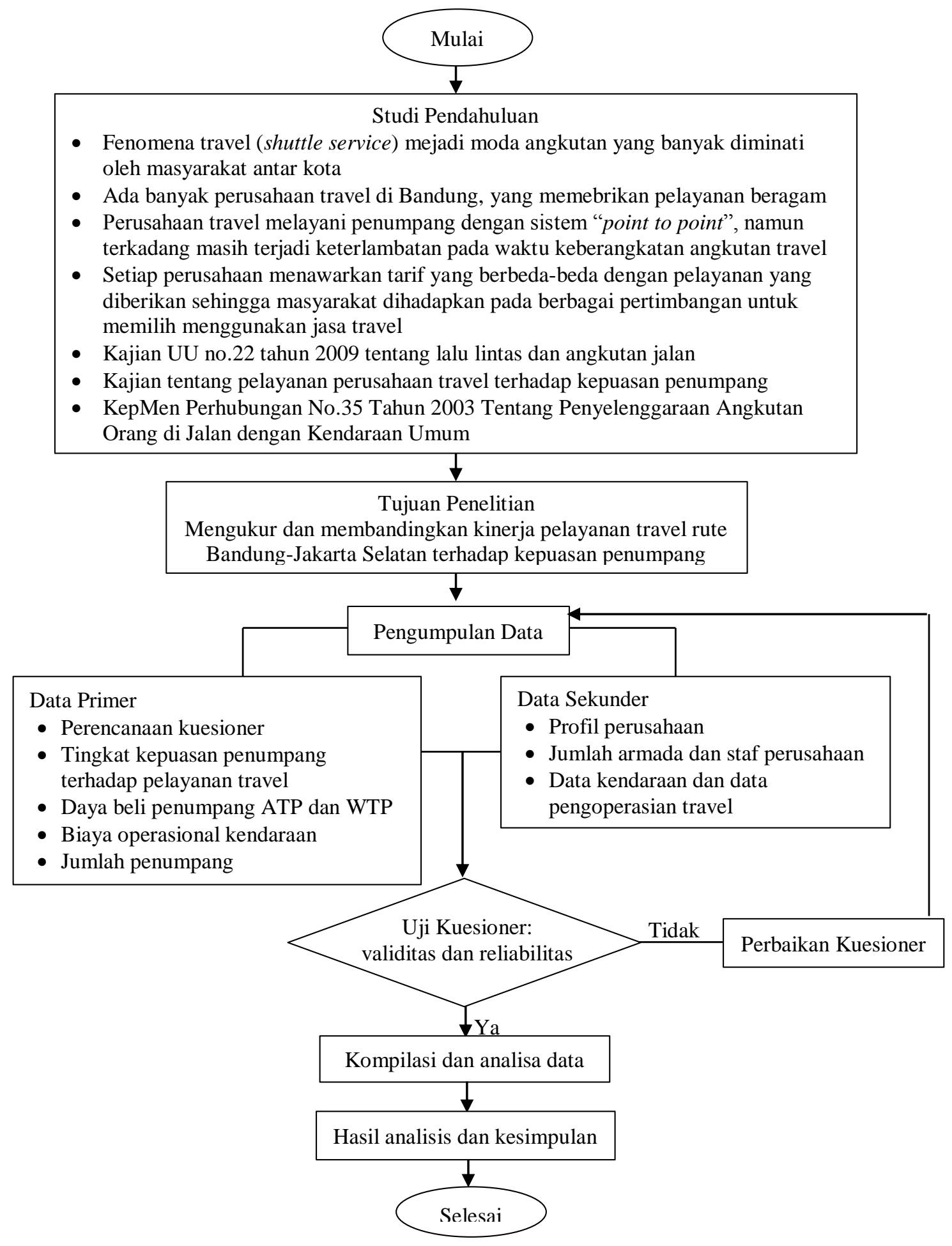

Gambar 1. Diagram Alir Penelitian 
Metode yang digunakan pada penelitian ini adalah metode kuantitatif yaitu metode penelitian yang menggunakan kuisioner sebagai alat untuk mengumpulkan data primer dengan mengambil sampel dari sebuah populasi.

Teknik analisis yang digunakan pada penelitian ini adalah statistik deskriptif . Alasan peneliti menggunakan metode statistik deskriptif karena dalam melaksanakan penelitian di travel (shuttle service) rute Bandung-Jakarta Selatan peneliti menggambarkan mengenai suatu kejadian atau fenomena yang terjadi di travel (shuttle service) rute Bandung-Jakarta
Selatan pada masa sekarang, kemudian tidak melakukan pengujian hipotesis, peneliti mengambil data dari travel (shuttle service) rute Bandung-Jakarta Selatan yang benarbenar representatif dan data tersebut mewakili objek penelitian.

Karena keterbatasan dana, tenaga, dan waktu, maka pada Tugas Akhir ini lingkup studi dibatasi pada rute Bandung-Jakarta Selatan. Adapun perusahaan travel (shuttle service) yang melayani rute perjalanan Bandung-Jakarta Selatan dapat dilihat pada Tabel 1.

Tabel 1. Daftar Seluruh Perusahaan Travel (shuttle service) Bandung-Jakarta Selatan

\begin{tabular}{ccccc}
\hline No & Nama Perusahaan & Alamat & Jml Kend & $\begin{array}{c}\text { Nama } \\
\text { Travel }\end{array}$ \\
\hline 1. & PT. Cipaganti Citra Graha & Jl. Gatot Subroto, Bandung & 262 & Cipaganti \\
2. & PT. Batara Titian Kencana & Jl. Cihampelas Bandung & 110 & X-Trans \\
3. & PT. Day Trans & Jl. Cihampelas & 70 & Daytrans \\
4. & PT. Nurrachmadi Bersama & Jl. Surapati & 60 & Baraya \\
5. & CV. Citra Tiara Transport & Jl. Dipati Ukur No. 53 & 75 & City Trans \\
\hline \multicolumn{7}{c}{ JUMLAH } & & $\mathbf{5 7 7}$ & \\
\hline
\end{tabular}

Sumber : Dinas Perhubungan Darat Kota Bandung

Berdasarkan Tabel di atas, di kota Bandung terdapat 5 perusahaan jasa travel (shuttle service) yang melayani rute perjalanan Bandung-Jakarta Selatan. Dari 5 perusahaan travel tersebut penelitian hanya dilakukan pada 3 perusahaan jasa travel saja dikarenakan 2 perusahaan travel lainnya tidak dimungkinkan untuk diteliti karena pihak perusahaan tersebut tidak memberikan izin untuk penelitian dan pengambilan data. Adapun 3 perusahaan jasa travel yang dapat diteliti, dapat dilihat pada tabel 2 .

Teknik sampling yang dilakukan adalah Probability Sampling. Pengambilan sampel menggunakan metode Simple Random sampling. Besarnya populasi penumpang travel pada bulan Juni sebanyak 4356 orang, sehingga untuk mengetahui besarnya sampel yang diambil dengan menggunakan taknik Solvin (Sugiyono, 2012) sebagai berikut:

$$
n=\frac{N}{1+N e^{2}}
$$

Keterangan :

$$
\begin{array}{ll}
\mathrm{n} & =\text { Jumlah Sampel } \\
\mathrm{N} & =\text { Jumlah Populasi } \\
\mathrm{e} & =\text { Tingkat kesalahan yang ditolerir } \\
& \text { (diambil sebesar 5\%) }
\end{array}
$$

Tabel 2. Daftar Travel (shuttle service) Bandung-Jakarta Selatan Yang Diteliti

\begin{tabular}{ccll}
\hline No & $\begin{array}{c}\text { Nama } \\
\text { Travel }\end{array}$ & $\begin{array}{c}\text { Alamat di } \\
\text { Bandung }\end{array}$ & $\begin{array}{c}\text { Alamat di } \\
\text { Jakarta } \\
\text { Selatan }\end{array}$ \\
\hline 1. & Cipagant & Jl. & Jl. Prof. Dr. \\
& i Travel & Cipaganti & Supomo No. 50, \\
& & No. 84 - & Pancoran - \\
& & Bandung & Jakarta Selatan \\
2. & X - & Hotel De & Jalan RS. \\
& Trans & Batara Jl. & Fatmawati No. \\
& Travel & Cihampela & 14B, Fatmawati \\
& & s No. 112 & - Jakarta \\
& & - Bandung & Selatan \\
3. & Day & Jl. & Jl. MT. Haryono \\
& Trans & Cihampela & Kav. 18 Tebet - \\
& Travel & S - & Jakarta Selatan \\
& & Bandung & \\
\hline
\end{tabular}

Sumber: Dinas Perhubungan Darat Kota Bandung 
Maka besarnya sampel untuk penelitian ini adalah :

$$
\begin{aligned}
& n=\frac{4356}{1+\left(4356 \times 0,05^{2}\right)} \\
& n=366,36
\end{aligned}
$$

Variabel yang digunakan dalam penelitian ini merupakan komponen pelayanan yang dapat diturunkan dari dimensi pelayanan sebagai berikut :

- Biaya perjalanan;

- Waktu tempuh perjalanan;

- Jadwal perjalanan;

- Kenyamanan pelayanan;

- Kompetensi pengemudi;

- Kelayakan armada;

- Keamanan dan keselamatan.

Selanjutnya dilakukan iji kuesioner untuk mengetahui apakah kuesioner mudah dipahami atau tidak oleh responden dengan cara diuji cobakan kepada calon penumpang sebelum pelaksanaan penelitian. Uji kuesioner terdiri dari uji validitas dan uji reliabilitas.

Pada tahap analisis data dilakukan dengan analisis statistik menggunakan metode Importance Performance Analysis dan uji sensitifitas.

\section{HASIL DAN PEMBAHASAN}

\section{Biaya Operasi Kendaraan (BOK)}

\section{Rekapitulasi Biaya Per Seat-KM}

- Biaya langsung

$\begin{array}{ll}\text { Biaya penyusutan } & =\text { Rp. } 28,97 \\ \text { Bungan modal } & =\text { Rp. } 0,00 \\ \text { Biaya awak kendaraan/mobil } & =\text { Rp. } 38,47 \\ \text { Biaya BBM } & =R p \cdot 101,85 \\ \text { Biaya ban } & =\text { Rp. } 45,00 \\ \text { Biaya pemeliharaan } & =\text { Rp. } 51,19 \\ \text { Biaya (STNK) } & =\text { Rp. } 1,34 \\ \text { Biaya KIR } & =\text { Rp. } 0,212 \\ \text { Biaya asuransi kendaraan } & =\text { Rp. } 4,53 \\ \text { Biaya AC Kendaraan } & =\text { Rp. } 2,00+ \\ \quad \text { Jumlah } & =R p \cdot 273,56\end{array}$

- Biaya tidak langsung = Rp. 28,35
- Total Biaya Per Penumpang

$=$ Rp. 301,91/ seat $-\mathrm{km}$

\section{ATP dan WTP Penumpang Travel}

Dari hasil perhitungan biaya operasional kendaraan travel rute Bandung-Jakarta Selatan dengan jarak tempuh kurang lebih $180 \mathrm{~km}$, diperoleh besarnya biaya pokok per kendaraan per km senilai Rp. 301,91, sedangkan tarif resmi yang berlaku saat ini adalah senilai $\mathrm{Rp}$. 555,56/seat-km. Maka selisih antara biaya pokok dengan tarif resmi yang berlaku saat ini kurang lebih 45,6\%.

\section{KESIMPULAN DAN SARAN}

\section{Kesimpulan}

Berdasarkan hasil perhitungan analisis data pada bab sebelumnya, maka dapat ditarik beberapa kesimpulan terkait dengan kepuasan penumpang travel (shuttle service) rute Bandung-Jakarta Selatan PP sebagai berikut :

- Berdasarkan hasil perhitungan BOK yang dilakukan pada bab 4 diperoleh besarnya biaya langsung per penumpang per seatkm sebesar Rp. 273,56 dan biaya tidak langsung per penumpang per seat-km sebesar Rp. 28,35. Sehingga total biaya per penumpang yakni biaya langsung ditambah biaya tidak langsung hasilnya sebesar Rp. 301,91/seat-km. Dengan tarif resmi yang berlaku saat ini sebesar Rp. 555,56/seat-km, maka selisih antara biaya pokok dengan tarif resmi yang berlaku saat ini kurang lebih 45,6\%. Hal ini menunjukkan nilai tarif resmi saat ini terlalu mahal.

- Berdasarkan grafik ATP dan WTP pada bab 4, diperoleh nilai tarif alternatif berdasarkan pada kondisi ATP dan WTP yang sama yakni sebesar Rp. 405,71/seat$\mathrm{km}$. Nilai tarif ini sama dengan nilai tarif yang diperoleh dari grafik keseimbangan biaya transportasi dan volume perjalanan. 


\section{Saran}

Berdasarkan analisis data dan kesimpulan yang telah dijelaskan, maka perlu adanya saran/masukan untuk perusahaan travel (shuttle service) rute Bandung-Jakarta PP dalam meningkatkan kinerja pelayanannya adalah perlu adanya perhitungan ulang mengenai tarif/biaya perjalanan yang merujuk pada aturan yang dikeluarkan oleh Dinas Perhubungan Darat mengenai ketentuan biaya operasional kendaraan. Hal ini berhubungan dengan besarnya tarif travel saat ini yang dianggap oleh beberapa penumpang masih terlalu mahal dan tidak sesuai dengan harapan.

\section{DAFTAR PUSTAKA}

Abubakar, dkk. (1997). Menuju Lalu Lintas dan Angkutan Jalan yang Tertib (Edisi yang disempurnakan). Direktorat Jenderal Perhubungan Darat: Jakarta.

Arikunto. (2008). Prosedur Penelitian Suatu Pendekatan Praktik. Jakarta: Rineka Karya.

Dinas Perhubungan Darat Kota Bandung. (2009). "Undang-undang Peraturan Pemerintah tentang Angkutan Jalan No. 22 tahun 2002 "'[Online]. Tersedia :http://dishub.jabarprov.go.id/doc/pp/p p_no_22_tahun_2009.pdf [04 Maret 2014].

Eka, Pratiwi. (2011). Analisis Tingkat Kepuasan Penumpang Atas Kualitas Pelayanan Travel Kartika Semarang. Tugas akhir pada program sarjana Teknik Sipil, Universitas Diponegoro Semarang: Tidak Diterbitkan.

Furqon. (2011). Statistik Terapan untuk Penelitian. Bandung: Alfabeta.

Hobbs, F.D. (1995). Traffic Planning and Engineering $2^{\text {nd }}$ Edition. England: Headingtown Hill Hall Oxford OX3 OBW.

Kamaluddin, Rustian. (2003). Ekonomi Transportasi. Jakarta: Ghalia Indonesia.

Keputusan Menteri Perhubungan Republik Indonesia nomor 35/MenHub/Kep/I/ 2003 tentang Penyelenggaraan Angkutan Orang di Jalan dengan Kendaraan Umum.
Kuncoro, Mudrajad. (2001). Metode Kuantitatif: Teori dan Aplikasi untuk Bisnis dan Ekonomi. Yogyakarta: UPP/ AMP YKPN.

Morlok, K, Edward. (1984). Introductions to Transportation Engineering and Planning. Diterjemahkan oleh Kelanaputra, Johan. tahun 1991 dengan judul Pengantar Teknik dan Perencanaan Transport. Jakarta: Erlangga.

Nurmalia, Maya. (2012). Analisis Pemilihan Moda Antara Bis Damri dan Travel (Arnes Shuttle) pada Perjalanan Bandung - Jatinangor. Jurnal Moda Transprotasi Angkutan Umum, Teknik Sipil ITB - Bandung. Hal.1

Peraturan Menteri Perhubungan Republik Indonesia nomor 10/Menhub/Per/II/ 2012 tentang Atribut Pelayanan.

Peraturan Pemerintah Republik Indonesia nomor 43/Pem/Per/I/1993 tentang Standar Load Factor.

Rahman, Rahmatang. (2009). Studi Pemilihan Moda Angkutan Umum Antara Kota Menggunakan Metode Stated Preference. Jurnal SMARTek, Vol. 7 No. 4. Hal. 230-231. . (2012). Analisa Biaya Oprasi (BOK) Angkutan Umum Antar Kota dalam Profinsi Rute Palu - Poso. Jurnal Rekayasa dan Manajemen Transportasi, Vol. II No. 1. Hal. 13-14.

Schumer. (1974). Planning for Public Transport. London: Huctchinson.

Sugiyono. (2012). Metode Penelitian Kuantitatif, Kualitatif dan $R \& D$. Bandung: Alfabeta.

Tamin, Ofyar. (2000). Perencanaan dan Pemodelan Transport edisi ke-2. Bandung: ITB.

Warpani, S. (1990). Merencanakan Sistem Perangkutan. Bandung: ITB. 